\title{
Sex differential in mortality trends of old-aged Danes: a nation wide study of age, period and cohort effects
}

\author{
Rune Jacobsen · Anna Oksuzyan · Henriette Engberg · \\ Bernard Jeune $\cdot$ James W. Vaupel $\cdot$ Kaare Christensen
}

Received: 26 March 2008/ Accepted: 15 September 2008/Published online: 7 October 2008

(C) Springer Science+Business Media B.V. 2008

\begin{abstract}
Objective Over the last half century the mortality rates in Denmark for females above age 80 have declined dramatically whereas the decline for males have been modest, resulting in a change in sex-ratio for centenarians from 2 to 5 . Here we investigate whether this mortality pattern is mainly explained by period effects, cohort effects or both. This can provide clues for where to search for causes behind the changes in sex differential in mortality seen in many Western countries during the last decades. Methods Age-period-cohort study of mortality for all Danish women and men aged 79-98 during the period 1949-2006. Outcome measures Relative risks for deaths and second order differences for exploration of the nonlinear variation. Results Both the overall trends in mortality differences and the fluctuations in mortality for both men and women were better explained by period effects than by cohort effects. The observed rates were better described by the age, period and cohort model than by other models. Conclusions Our results suggest that causes for both the overall increased difference in mortality and the short term fluctuations in mortality rates are primarily to be found in the period dimension. Cohort effects on the mortality of the oldest Danish women and men played a significant but minor role compared to period effects.
\end{abstract}

R. Jacobsen $(\bowtie) \cdot$ A. Oksuzyan · H. Engberg ·

B. Jeune $\cdot$ K. Christensen

Institute of Public Health, Epidemiology, University of Southern

Denmark, J.B. Winsløws Vej 9B, 5000 Odense C, Denmark

e-mail: rjacobsen@health.sdu.dk

A. Oksuzyan · J. W. Vaupel

Max Planck Institute for Demographic Research,

Konrad-Zuse-Str. 1, 18057 Rostock, Germany
Keywords Age-period-cohort modeling . Old age mortality $\cdot$ Sex differential $\cdot$ Denmark

\section{Introduction}

There is a sex differential in mortality in favor of women all over the world and most pronounced in Western world countries [1, 2]. With economic development and improved living conditions for females, the sex gap in mortality favoring women has been increasing through the first three quarters of the twentieth century in most Western countries [3-5], including Denmark and other Nordic countries [6,7]. However, findings of sex differences in mortality development in the developed countries during the last quarter of the twentieth century have been mixed. Female-male differences in life expectancy narrowed in most European countries and in the US from 1980 to 1996, but the sex gap became even larger in other countries such as Greece, Hungary, Russian Federation and Japan [8-10].

A number of explanations proposed to explain sex differences in mortality are rooted in biological, psychological, and social interpretations. Among the most prominent biological explanations are the hormonal, autoimmune and genetic explanations [11]. The observation that males have a rise in cardiovascular disease approximately 10 years before females combined with the known favorable effect of estrogen on serum lipids [12] and its protective effect on brain cells [13] and consequent prevention of degenerative processes, has led to the hypothesis that estrogen is a central factor in the paradox. According to the X-chromosome hypothesis, the lack of a second $\mathrm{X}$ chromosome in the male is associated with increased mortality [11, 14]. Finally, the "immunocompetence" hypothesis states that increased male mortality throughout 
life may be caused in part by a greater susceptibility of males to infections $[15,16]$.

The social and behavioral factors, such as differences in social roles and behaviors, illness behavior, physician behavior and behavior related to health care utilization, have also been suggested to explain female-male differences in mortality [17]. Research has consistently demonstrated that men engaged more frequently in higher risk-taking behavior such as cigarette smoking, higher alcohol consumption, more frequent use of psychoactive substances, and less safe driving that contributed to an increased risk of coronary heart disease (CHD), lung cancer, chronic obstructive pulmonary diseases, liver cirrhosis, and accident fatalities in men compared to women [18]. There is a general agreement that cigarette smoking is the single largest identifiable factor in explaining increasing sex gap in mortality, but it is well established also that cigarette smoking alone cannot fully explain the sex difference in and the trajectories of mortality. The simple observation that there is still a sex difference in survival among never-smokers illustrates this [8-10]. Besides, recently it was found that the traditional risk factors for increased mortality such as social position and education had no or only very limited effect on the oldest-old mortality in Denmark [19].

For both men and women living in developed countries there has been a marked increase in life expectancy during the last century, especially at older ages [20-23]. The number of centenarians has increased steadily in most developed countries [24-26]. The reason for the improvement in longevity seems mostly to be due to a reduction in mortality at advanced ages [27-30]. It has recently been debated whether mostly cohort effects or period effects are responsible for this increase in longevity [31, 32]. Cohort effects are effects acting on specific generations whereas period effects act on more age groups living at a specific point in time. The 'period hypothesis on longevity' argues that changes in period effects acting at advances old age are the reason for the decrease in mortality seen in the many countries in the Western world during the last decades [33]. The Barker hypothesis [34] or the 'diminished entelechy hypothesis' [35] suggest that somatic insults in intrauterine life and early childhood predispose to increased morbidity and mortality in adulthood. The 'inflammatory cohort hypothesis on longevity' states that inflammatory exposure in childhood is associated with increased mortality at old age, and that the decrease in inflammatory exposure in childhood during the lasts centuries with each consecutive birth cohort is the reason for the observed reduction in mortality at advanced ages [31].

In this study we compared the mortality pattern of Danish women with that of Danish men to examine the increased sex differential in late life mortality during recent decades. We addressed the question if mostly period effects or cohort effects act on late life mortality patterns. In the search for causes behind the trends in the sex differential in mortality and in overall late life mortality it would be informative to know whether these causes are to be searched for in a period or a cohort perspective. If period effects are dominant, causes acting at the particular point in time should be searched for, whereas cohort effects point towards causes clustered to specific generations. For example, if inflammatory diseases in childhood in a given birth cohort are associated with old age mortality for that cohort, the mortality for men and women in the same cohort would be expected to show similar patterns if inflammatory diseases were not sex-specific.

\section{Methods}

Number of deaths and mid-year population, stratified by 1-year groups, for all Danish women and men aged 79-98 in the period 1949-2006 was obtained from the human mortality database [36]. The reason for choosing this age range was that information on population size was only available until age 98 and when using 2-year categories for age, the starting point became 79 years. The data were organised in a two-way table with rows as 2-year age groups and columns as 2-year-period groups and approximate birth cohorts represented by the diagonals of the table. Within the 2-year age and period groups, the persons contributing to such a cohort were born within a 4-yearperiod, and the same persons contributed to two adjacent approximate birth cohorts.

Plots of observed mortality rates stratified by 2 -year age groups and by sex were made in order to examine if the offset for the increased sex differential in mortality rates was initiated at the same point in time for all age groups (indicating a period effect) or if it was delayed by 2 years with each consecutive age group (indicating a cohort effect).

In order to select an appropriate model for the description of the observed mortality rates, a similar approach as the scheme given by Clayton and Schifflers [37, 38] was used (Fig. 1). In the pure age model, no temporal change is present (i.e. no change in mortality neither over time nor for specific generations). In the age-period model, the agespecific logarithms of the mortality rates are increased (or decreased) from one period to the other by the same quantity regardless of age. This is for example the case when a new exposure enters at some calendar time and exerts the same effect over all ages. When exposures are clustered by generation, then on a logarithmic scale the age-specific differences in mortality between any pair of cohorts are approximately constant for all ages, and the 


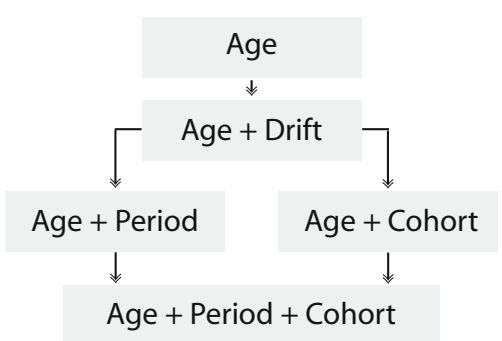

Fig. 1 Model selection scheme used in this study. The pure age model is compared with the age-drift model to test for linear components. The age-drift is compared with the age-period and agecohort to test for irregularities attributable to cohort and period, respectively. If none of these models describe the data well, the ageperiod-cohort model should be tried

age-cohort model is expected to give the best fit. In the special case where the data are equally well described by an age-period or an age-cohort model, the age-drift model is used, where the drift is an effect that cannot be distinguished between period and cohort. When the age-period and the age-cohort models do not describe the data well, then the age-period-cohort model should be tried [37].

The mortality for the period 1949-2004 was analysed using age-period, age-cohort and age-period-cohort modeling. The age-period-cohort technique aims to solve the problem that the age, period and cohort effects cannot simply be estimated in the same model as they are linearly dependent on each other [39]. To meet this problem the linear components of age, period and cohort and parameters associated with deviation of the effects of each of these factors from linearity can be examined [39, 40]. We used the following model to examine the effects of age, period and cohort:

$\log \left(\right.$ rate $\left._{i j}\right)=\mu+\alpha_{i}+\beta_{j}+\varepsilon_{c}$

where $\mu$ represents the mean effect (intercept), $\alpha_{i}$ the effect of age group $i, \beta_{j}$ the deviation from linearity of the $j$ th period, $\varepsilon_{c}$ the deviation from linearity of the $c$ th cohort.

Formal goodness-of-fit analysis comparing the observed deviance to the relevant $\chi^{2}$-distribution requires some care for these data based on a complete national population, as conventional significance levels are not necessarily helpful, as these analyses were developed for relatively small sample sizes. This problem was approached by plotting expected rates based on the different models and the observed mortality rates.

In the age-period-cohort model, the overlap of data between adjacent approximate cohorts makes interpretation of the change in the nonlinear effect from one category to the next difficult. However, second order changes based on the estimates from the age-period-cohort models can be used to examine the nonlinear effects and overcome the problem of the overlap of adjacent cohorts [37, 39, 41].
Second order differences were calculated using the formula:

$\prod_{i}-2 \prod_{i+1}+\prod_{i+2}$

where $\Pi_{i}$ is the $i$ th parameter.

The parameters of the models were estimated using multiplicative Poisson regression models [42] and all statistical analyses were done using the SAS 9.1 package [43].

\section{Results}

There was an overall decline in mortality rates for both Danish women and men during the last half of the twentieth century (Fig. 2). However, around 1960, acceleration in the decline began for women aged 79-92 independently of age group. This step decline was not seen for men and led to the increase in the overall sex differential in mortality. For persons above 92 years the pattern was fluctuating (Fig. 3) illustrating the low number of survivors at these extreme ages. Also, the fluctuations in the mortality pattern (i.e. between adjacent year groups) showed a similar pattern independently of sex and age group (Fig. 3).

The fit for the different models are shown in Table 1. There was a better fit for the age-period model than for the age-cohort model for both men and women with the better fit being most pronounced for women (Table 1). The ageperiod-cohort model significantly increased the fit for the model for both sexes $(P>0.001)$. The model deviances were 1.7 and 1.2 for women and men, respectively, times the relevant degrees of freedom (172), which is a remarkably good fit for national mortality data. When calculating the expected rates of the different models (Fig. 4), the age-period model showed a much closer fit to the observed rates compared with the age-cohort model. The best fit to the observed rates was obtained by the ageperiod-cohort model for both men and women (Fig. 4).

The 2nd differentials based on the estimates from the age-period-cohort models showed an overall stronger influence of period effects compared with cohort effects (Fig. 5). The acceleration and deceleration in the mortality by period groups showed a nearly identical pattern for women and men. For cohort groups the pattern was much more sex-specific even though the same acceleration and deceleration by cohort groups was found around 1918 and 1920.

\section{Discussion}

The overall patterns of the sex differential in mortality of the oldest old Danes suggest a strong influence of both 
Fig. 2 Crude death rates for Danish women and men aged 79-98 from 1949 to 2006

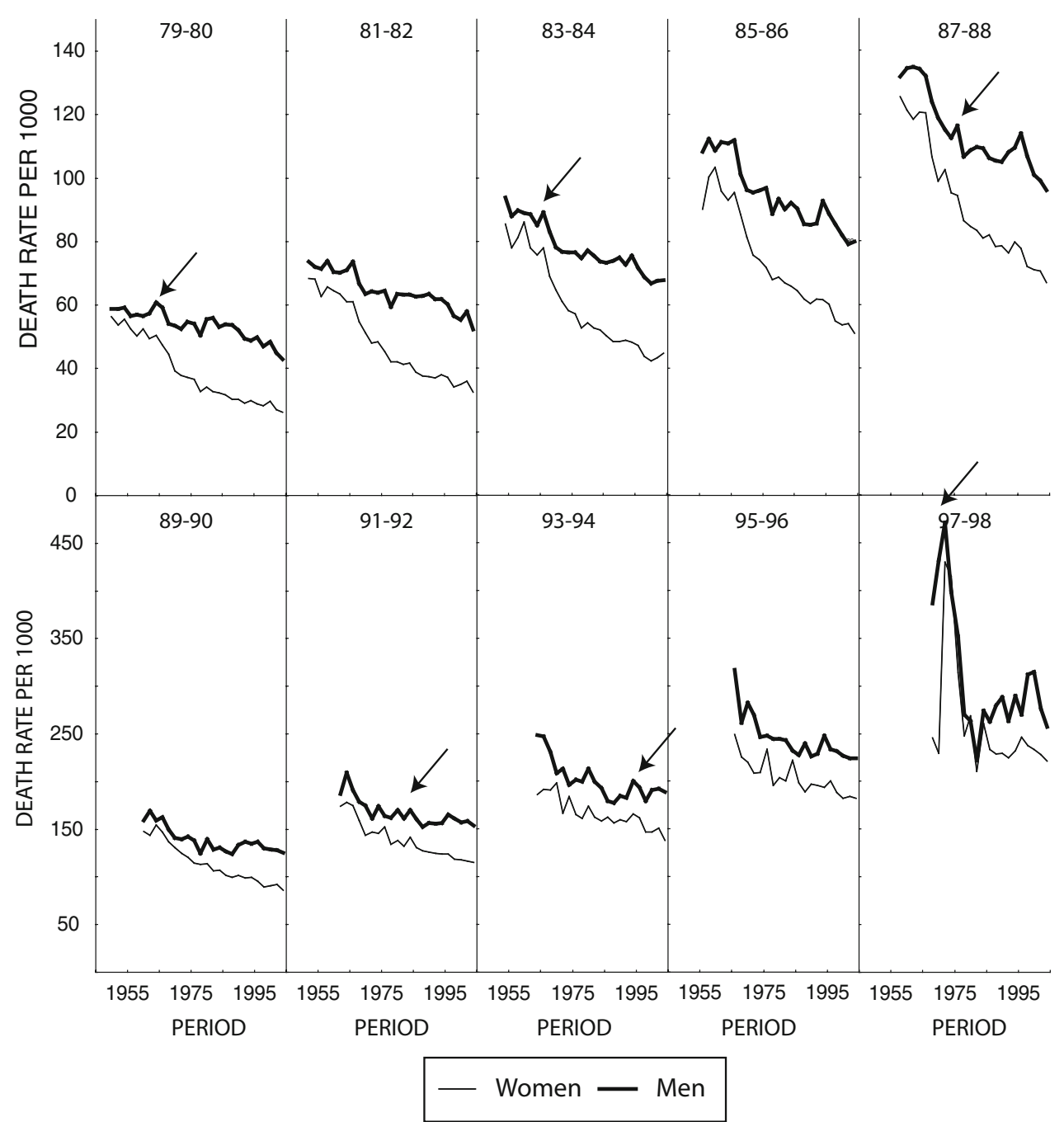

nonlinear and linear period effects. The same offset over age categories is observed and the formal representation in different models points mostly towards causes acting in the period dimension for the marked increase in sex differential in mortality since the 1960s. Cohort effects increased the overall formal fit when included in the model. Also, the inclusion of cohort resulted in a slightly better fit when evaluating observed and expected rates, signifying some influence of cohort effects on the nonlinear variation in the sex-specific mortality. However, generally the overall increase in the fit by including period was much larger than when including cohort. This suggests that a future search for underlying causes for sex differentials in old age mortality in Denmark should mostly focus on causes acting in the period dimension for both nonlinear and linear effects.

Whereas the nonlinear variation in cohort effects has previously been shown to have a large effect on the mortality of middle-aged women in Denmark [44], such effects seem to have diminished in old age. This supports the finding/assumption that cohort effects are reduced in old age as suggested by Kannisto [45].

The nonlinear patterns for men and women represented by second order differences had very similar patterns when shown in the period dimension, and limited or no similarities when presented in the cohort dimension. This is opposite to what is suggested by the 'inflammatory cohort hypothesis on longevity' [31] which would predict similar nonlinear mortality patterns for cohorts of men and women exposed to the same inflammatory stimuli at childhood.

The study showed that even with the well-known unidentifiability problems in the age-period-cohort analysis due to the perfect correlation when all three are included in the model, an exploration in this framework can provide useful information on where to search for causes for observed mortality patterns, especially when short term fluctuations are seen in the mortality patterns (e.g. between years or cohorts). The credibility of age-period-cohort modeling in the analysis of mortality in Denmark has previously been shown [44] together with the possibility to 
Fig. 3 Crude death rates for Danish women and men aged 79-98 from 1949 to 2006
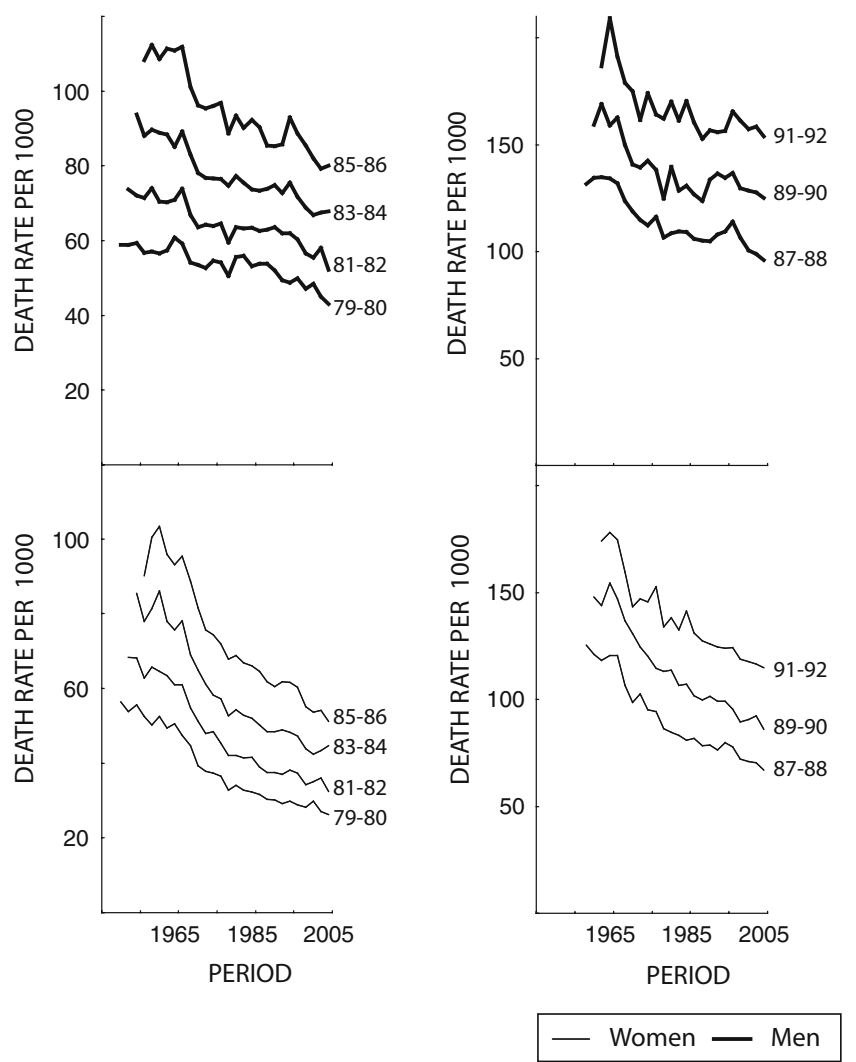

Table 1 Model fit for the different models

\begin{tabular}{lrrr}
\hline Separate models & DF & Value & $\begin{array}{l}\text { Value/ } \\
\text { DF }\end{array}$ \\
\hline Women & & & \\
$\quad$ Age & 225 & 20617 & 91.6 \\
Age-drift & 224 & 1924 & 8.6 \\
Age-period & 198 & 638 & 3.2 \\
Age-cohort & 198 & 1371 & 6.9 \\
Age-period- & 172 & 287 & 1.7 \\
cohort & & & \\
Men & & & \\
Age & 225 & 3474 & 15.4 \\
Age-drift & 224 & 799 & 3.6 \\
Age-period & 198 & 464 & 2.3 \\
Age-cohort & 198 & 480 & 2.4 \\
Age-period- & 172 & 203 & 1.2 \\
cohort & & & \\
\hline
\end{tabular}

compare more nations in the analysis [46]. For future analysis of sex differentials in mortality it could be supportive to use the multinational method to elude differences among countries, and this might provide further clues on which causes are acting on late life mortality.

In this study we found increasing sex differentials in mortality for all age groups with an offset around 1965 in favor of women. This strongly suggests that mostly period

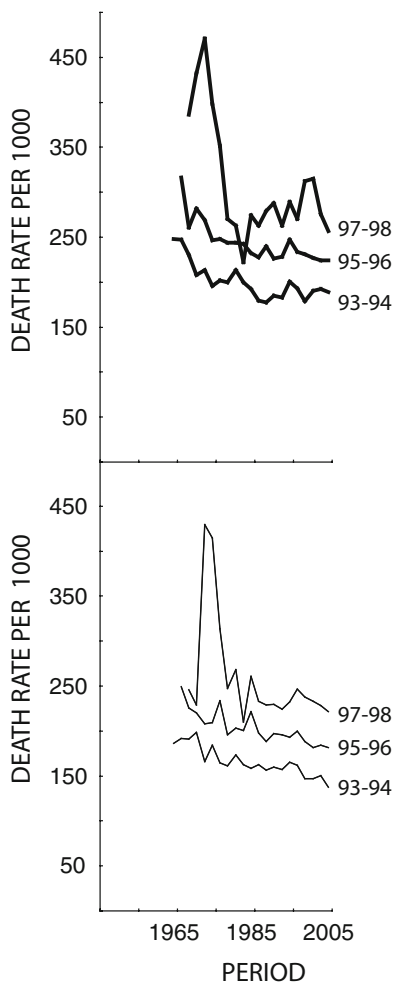

effects are responsible for the increase in the sex differential during the study period. A plausible candidate for the increase in sex-specific differences is smoking behaviour. It has previously been suggested that smoking is principally responsible for the change in the pattern of sex mortality differences in the United States [9]. If smoking is the principle factor responsible for the observed change in the pattern of sex mortality differences among the oldest old in Denmark, it suggests that men in all age groups started smoking more than women at the approximate same point in calendar time. If it is assumed that the consequences on mortality due to smoking begin to show approximately 20 years after smoking onset, this suggests that Danish men in all age groups started smoking after the Second World, whereas Danish women had lower smoking prevalence than men. Moreover, it suggests that the effect of the post-war differences in the smoking behavior of Danish women and men on mortality have increased over the following 40 years. Data available on smoking behavior from the 1950s support the assumption that Danish men had a high smoking prevalence in all age groups after the Second World War whereas the prevalence declined with age for women [47] (Fig. 6a). Men belonging to the generations taking on smoking immediately after the Second World War still have a markedly higher smoking prevalence than women in the 1970s (i.e. the oldest age groups in Fig. 6b). Thus, the data indicate that men 


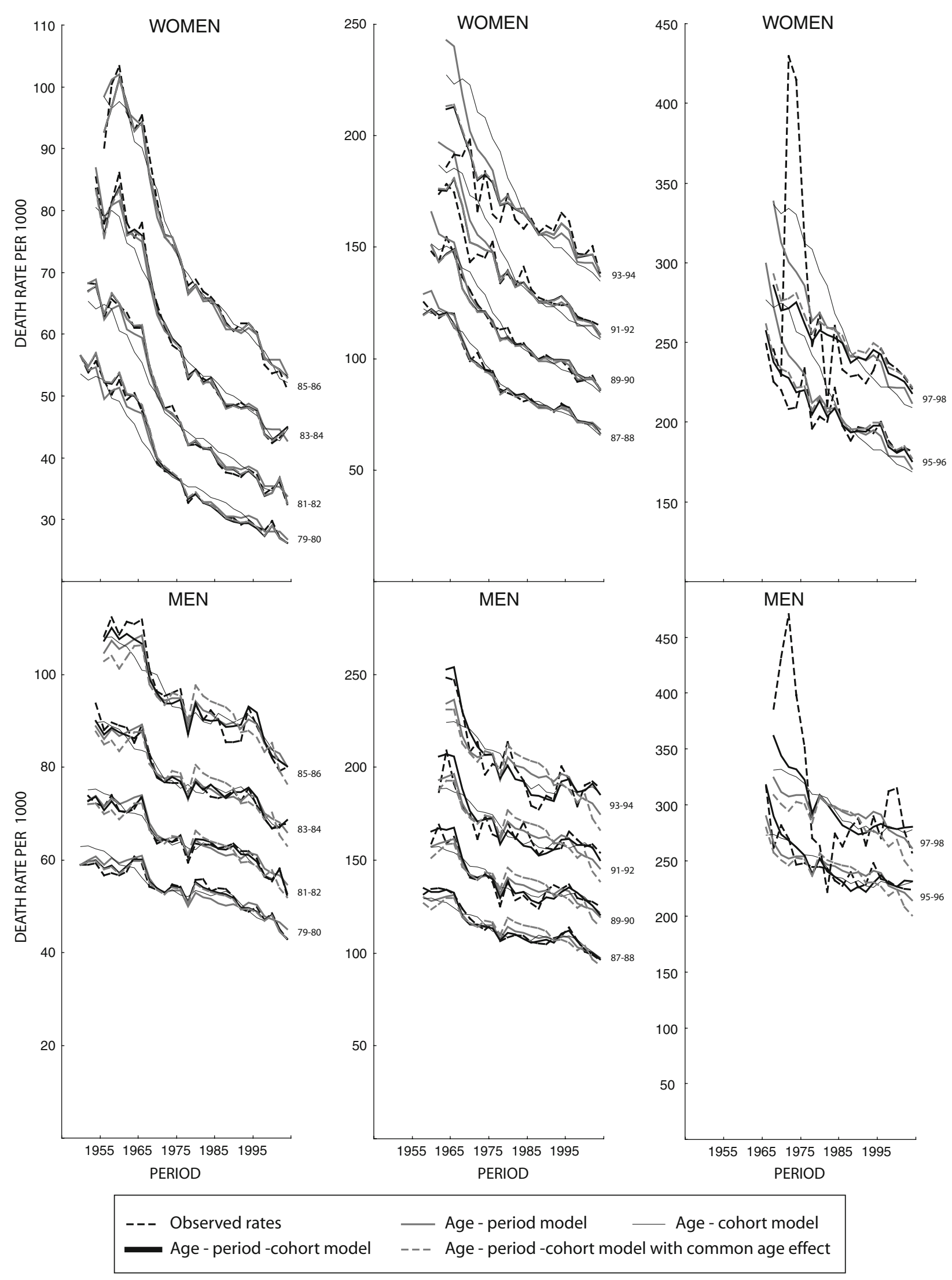

Fig. 4 Observed and expected death rates based on different models 
Fig. 5 Second order differences of the parameter estimates by period and cohort
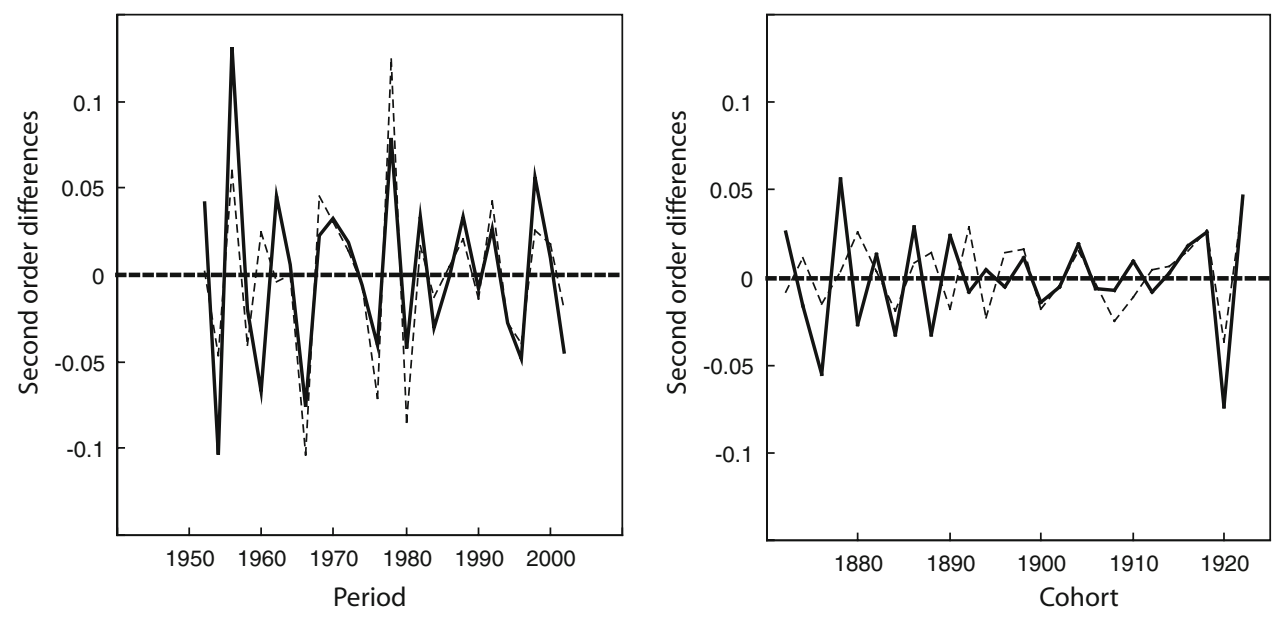

- Men -.- Women

1953
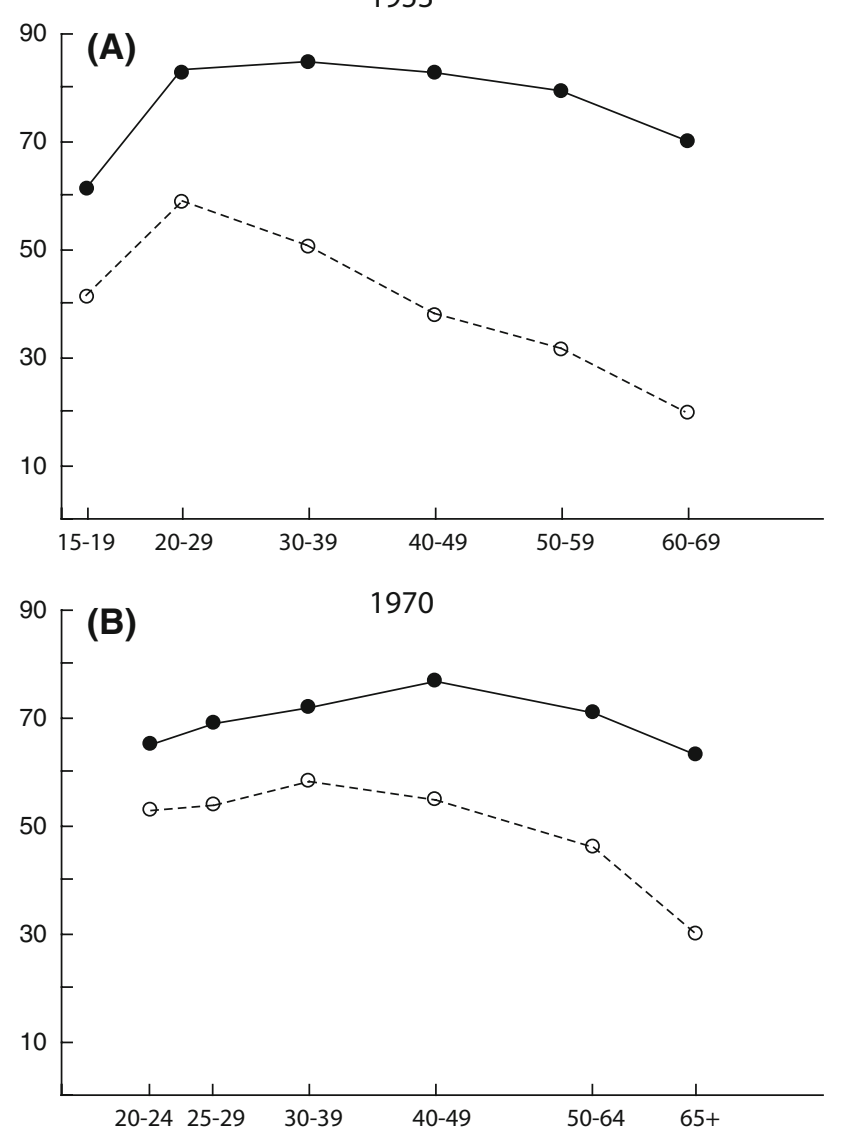

Fig. 6 Smoking prevalence for Danish women and men over age groups in (a) 1953 and (b) 1970

independently of age smoked more than women after the Second World War and continued to do so throughout life whereas women had an age-dependent smoking pattern after the Second World War with markedly lower smoking prevalence throughout life for the women in the present study [46]. This suggest towards smoking as an important factor for the observed increase in the sex differential in mortality among the oldest old in Denmark beginning around 1965. This finding is further supported by data on smoking behavior from two nationwide studies of the oldest old in Denmark [48]. Among 95 and 100-year-old men born in 1885 and $1905,75 \%$ and $73 \%$, respectively, had been smokers whereas the equivalent numbers for women were $32 \%$ and $34 \%$ [48]. Unfortunately, we do not have information on causes of death from these studies and therefore the interrelationship between smoking behavior and mortality remains somewhat speculative.

In conclusion, the age-period-cohort analysis has, in this study, proved useful as a tool for testing hypothesis addressing influences of period and cohort. The findings in this study suggest that causal factors acting on sex differentials in mortality at old age are mostly to be searched for in the given period.

\section{References}

1. Vallin J. Social change and mortality decline: women's advantage regained or achieved? Oxford: Clarendon Press; 1993.

2. Barford A, Dorling D, Davey SG, Shaw M. Life expectancy: women now on top everywhere. BMJ. 2006;332(7545):808. doi: 10.1136/bmj.332.7545.808.

3. Nathanson CA. Illness and the feminine role: a theoretical review. Soc Sci Med. 1975;9(2):57-62. doi:10.1016/0037-7856 (75)90094-3.

4. Preston SH. Mortality patterns in national populations: with special reference to recorded causes of death. New York: Academic Press; 1976.

5. Waldron I. What do we know about causes of sex differences in mortality? A review of the literature. Popul Bull UN. 1985; 18:59-76.

6. Rigby JE, Dorling D. Mortality in relation to sex in the affluent world. J Epidemiol Community Health. 2007;61(2):159-64. doi: 10.1136/jech.2006.047381. 
7. Helweg-Larsen K, Juel K. Sex differences in mortality in Denmark during half a century, 1943-92. Scand J Public Health. 2000;28(3):214-21.

8. Waldron I. Recent trends in sex mortality ratios for adults in developed countries. Soc Sci Med. 1993;36(4):451-62. doi: 10.1016/0277-9536(93)90407-U.

9. Preston SH, Wang H. Sex mortality differences in the United States: the role of cohort smoking patterns. Demography. 2006;43(4):631-46. doi:10.1353/dem.2006.0037.

10. Gjonca A, Tomassini C, Toson B, Smallwood S. Sex differences in mortality, a comparison of the United Kingdom and other developed countries. Health Stat Q. 2005;26:6-16.

11. Austad SN. Why women live longer than men: sex differences in longevity. Gend Med. 2006;3(2):79-92. doi:10.1016/S15508579(06)80198-1.

12. Waldron I. Contributions of biological and behavioral factors to changing sex differences in ischemic heart disease mortality. Adult mortality in developed countries: from description to explanation. Oxford: Oxford University Press; 1995.

13. McEwen BS, Alves SE. Estrogen actions in the central nervous system. Endocr Rev. 1999;20(3):279-307. doi:10.1210/er.20. 3.279 .

14. Christensen K, Kristiansen M, Hagen-Larsen H, Skytthe A, Bathum L, Jeune B, et al. X-linked genetic factors regulate hematopoietic stem-cell kinetics in females. Blood. 2000;95(7):2449-51.

15. Owens IP. Ecology and evolution. Sex differences in mortality rate. Science. 2002;297(5589):2008-9. doi:10.1126/science. 1076813.

16. Crimmins EM, Finch CE. Commentary: do older men and women gain equally from improving childhood conditions? Int J Epidemiol. 2006;35(5):1270-1. doi:10.1093/ije/dyl194.

17. Wingard DL. The sex differential in morbidity, mortality, and lifestyle. Annu Rev Public Health. 1984;5:433-58. doi:10.1146/ annurev.pu.05.050184.002245.

18. Waldron I. An analysis of causes of sex differences in mortality and morbidity. The fundamental connection between nature and nurture. Lexington, MA: Lexington Books; 1982.

19. Nybo H, Petersen HC, Gaist D, Jeune B, Andersen K, McGue M, et al. Predictors of mortality in 2, 249 nonagenarians - the Danish 1905-Cohort Survey. J Am Geriatr Soc. 2003;51(10):1365-73. doi:10.1046/j.1532-5415.2003.51453.x.

20. Kannisto V. The advancing frontier of survival: life tables for old age., Odense monographs on population aging 3. Odense: Odense University Press; 1996.

21. Oeppen J, Vaupel JW. Demography. Broken limits to life expectancy. Science. 2002;296(5570):1029-31. doi:10.1126/science. 1069675.

22. Vaupel JW, Carey JR, Christensen K, Johnson TE, Yashin AI, Holm NV, et al. Biodemographic trajectories of longevity. Science. 1998;280(5365):855-60. doi:10.1126/science.280.5365.855.

23. Wilmoth JR, Deegan LJ, Lundstrom H, Horiuchi S. Increase of maximum life-span in Sweden, 1861-1999. Science. 2000; 289(5488):2366-8. doi:10.1126/science.289.5488.2366.

24. Jeune B, Vaupel JW. Exceptional longevity: from prehistory to the present, Odense monographs on population aging 2. Odense: Odense University Press; 1995.

25. Kannisto V. The advancing frontier of survival: life tables for old age. Odense: Odense University Press; 1996.

26. Robine JM, Vaupel JW, Jeune B, Allard M. Longevity: to the limits and beyond. Berlin: Springer; 1997.

27. Grundy E. Mortality and morbidity among the old. Br Med J (Clin Res Ed). 1984;288(6418):663-4.
28. Manton KG. Changing concepts of morbidity and mortality in the elderly population. Milbank Mem Fund Q Health Soc. 1982; 60(2):183-244. doi:10.2307/3349767.

29. Rothenberg R, Lentzner HR, Parker RA. Population aging patterns: the expansion of mortality. J Gerontol. 1991;46(2):S66-70.

30. Vaupel JW, Lundström H. The future of mortality at older ages in developed countries. In: Lutz W, editor. The future population of the world: what can assume today? London: Earthscan Publications; 1994. p. 295-315.

31. Finch CE, Crimmins EM. Inflammatory exposure and historical changes in human life-spans. Science. 2004;305(5691):1736-9. doi:10.1126/science.1092556.

32. Barbi E, Vaupel JW. Comment on "Inflammatory exposure and historical changes in human life-spans". Science. 2005;308(5729): 1743. doi: $10.1126 /$ science. 1108707.

33. Kannisto V. The advancing frontier of survival: life tables for old age. Odense: Odense University Press; 1996.

34. Barker DJP. Mothers, babies and health in later life. 2nd ed. Edinburgh: Churchill Livingstone; 1998.

35. Catalano R, Bruckner T. Child mortality and cohort lifespan: a test of diminished entelechy. Int J Epidemiol. 2006;35(5):1264-9. doi:10.1093/ije/dyl108.

36. Human Mortality Database. University of California, Berkeley (USA), and Max Planck Institute for Demographic Research (Germany). 2007. www.mortality.org. Ref Type: Data File.

37. Clayton D, Schifflers E. Models for temporal variation in cancer rates, II: age-period-cohort models. Stat Med. 1987;6(4):469-81. doi:10.1002/sim.4780060406.

38. Clayton D, Schifflers E. Models for temporal variation in cancer rates. I: age-period and age-cohort models. Stat Med. 1987;6(4): 449-67. doi:10.1002/sim.4780060405.

39. Holford TR. Analysing the temporal effects of age, period and cohort. Stat Methods Med Res. 1992;1(3):317-37. doi:10.1177/ 096228029200100306.

40. Robertson C, Boyle P. Age-period-cohort analysis of chronic disease rates, I: modelling approach. Stat Med. 1998;17(12): 1305-23. doi:10.1002/(SICI)1097-0258(19980630)17:12<1305:: AID-SIM853>3.0.CO;2-W.

41. Tango T, Kurashina S. Age, period and cohort analysis of trends in mortality from major diseases in Japan, 1955 to 1979: peculiarity of the cohort born in the early Showa Era. Stat Med. 1987;6(6):709-26. doi:10.1002/sim.4780060608.

42. Breslow NE, Day NE. Methods in cancer research, the design and analysis of cohort studies. Lyon: IARC Scientific Publications No. 82; 1987.

43. SAS. Version 9.1. Cary, NC: SAS Institute; 2005

44. Jacobsen R, Keiding N, Lynge E. Long term mortality trends behind low life expectancy of Danish women. J Epidemiol Community Health. 2002;56(3):205-8. doi:10.1136/jech.56.3.205.

45. Kannisto V. The advancing frontier of survival: life tables for old age. Odense: Odense University Press; 1996.

46. Jacobsen R, Von EM, Osler M, Lynge E, Keiding N. Women's death in Scandinavia-what makes Denmark different? Eur J Epidemiol. 2004;19(2):117-21. doi:10.1023/B:EJEP.0000017834. 35943.bd.

47. Marie L. Sygdomsunders $\varnothing$ gelsen i Danmark 1951-1954: En statistisk analyse af den almindelige sygelighed samt enkelte andre forhold i forbindelse dermed. Munksgaard; 1960.

48. Jeune B. Explanation of the decline in mortality among the oldest-old: the impact of circulatory diseases. In: Robine JM, Crimmins EM, Horiuchi S, Yi Z, editors. Human longevity, individual life duration and the growth of the oldest-old population. Dordrecht: Springer; 2006. 